\title{
Science Policy, Planning, Research and Implementation: Are we able to Achieve what we Want and what is Needed?
}

Pandey JS*

Chief Scientist and Head, Climate Change, CSIR-National Environmental Engineering Research Institute (NEERI), Nagpur-440020, India

*Corresponding author: Pandey JS, Chief Scientist and Head, Climate Change, CSIR-National Environmental Engineering Research Institute (NEERI), Nagpur-440020, India, Tel: 0712-2249885; E-mail: js_pandey@neeri.res.in

Rec date: April 11, 2016; Acc date: April 13, 2016; Pub date: April 18, 2016

Copyright: @ 2016 Pandey JS. This is an open-access article distributed under the terms of the Creative Commons Attribution License, which permits unrestricted use, distribution, and reproduction in any medium, provided the original author and source are credited.

\section{Editorial}

The most important term above is "what we want"? I often times wonder how many sspeople can exactly answer this question i.e., what exactly do we want? The answers would be as many as the no. of people we have on this planet. Moreover, the answers will have diurnal, seasonal and annual variations. In short, the answers will vary from one place to another and from one time-frame to another.

But one thing we can certainly do with these answers. And, that is the best thing we can do. We can use these answers to find out the average-requirements of a particular region. Now, let us ask ourselvesare we doing this kind of region-specific assessments? Have we done it earlier? The answers would be obvious. Frankly speaking, how many of us really worry and think about this assessment-most of us obsessed and bogged down as we are with our own problems and assessments. So somehow someone has to bell the cat and do this assessment so as to make our planning process more meticulous and meaningful.

Subsequently, we will have to formulate and take appropriate policy decisions. This can be done in the following two ways: First approach could be to formulate a policy, take a decision and then ask people to follow and implement. However, there are few uncertainties and hiccups here. Firstly, how are we sure that people will follow the decision (for all we know this may not be of the kind which was desired by them). And we know that our foremost duty is to cater to the needs of the common man. So we cannot ignore their aspirations. This once again reiterates the need for their "accurate needassessment". Therefore, every science policy should start with this kind of a socio-environmental need-assessment study.

The second problem which we encounter more often than not is the implementation of policy decisions. And of all the factors which are responsible for non-implementation or delayed implementation, one reason which is most prominently common all through this process is that either we do not have the "appropriately" skilled persons or the right people are not doing the right thing at the right place with the right intention.

Under these circumstances probably the role of technology becomes much smaller. And that of motivation increases manifold. Therefore, as it may sound quite logical, we may have to spend more time and energy in motivating people. This indirectly means that until unless there is right and appropriate motivation, the fruits of invention and innovation cannot be realized-be it in the field of medicine, agriculture, defense related equipments, energy, economics or environment.

Let us give a serious thought to it. 